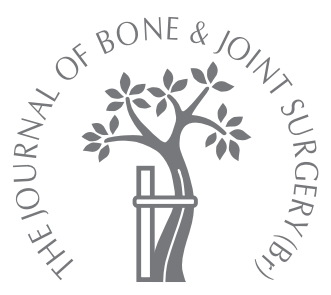

K. Wong,

T. P. Ng,

K. Y. Chiu

From Queen Mary

Hospital, Hong Kong
- CASE REPORT

\section{Hip pain many years after fusion}

\author{
A REPORT OF TWO CASES
}

K. Wong, MBBCh,

$B A O$ (Ireland), MRCS(Ireland), Resident

I. P. Ng, FRCSE, FRCSE(Orth), FHKAM(Ortho), Associate Consultant and Honorary Assistant Professor, Chief, Division of General

Orthopaedics and Oncology

K. Y. Chiu, FRCS(Ed), FHKAM (Ortho), Professor, Chief,

Division of Joint Replacement

Surgery

Department of Orthopaedics

and Traumatology

Queen Mary Hospital, 102

Pokfulam Road, Hong Kong,

SAR, China.

Correspondence should be sent to Dr K. Wong; e-mail: shinoske@netvigator.com

(c2008 British Editorial Society of Bone and Joint Surgery doi:10.1302/0301-620X.90B4. $20120 \$ 2.00$

$J$ Bone Joint Surg $[\mathrm{Br}]$ 2008;90-B:510-11.

Received 21 August 2007;

Accepted 1 November 2007

\begin{abstract}
Arthrodesis of the hip has been employed since the late 19th century. Late complications can arise decades after fusion in patients who were previously asymptomatic. We describe two patients who developed pain in the hip many years after a successful fusion. There was no infection or loosening of the implants. After careful investigation, including oblique radiographs and diagnostic injections of local anaesthetic, the pain was found to be caused by protrusion of the implant. Subsequent removal of the device resulted in complete resolution of the symptoms.
\end{abstract}

Arthrodesis of the hip was first described in the late $1800 s^{1}$ and many different techniques have since been used. The objective is to obtain a stable and pain-free joint. We describe two patients, treated by arthrodesis of the hip many years ago, who presented with hip pain. Although pain after hip fusion is not uncommon, careful clinical assessment and investigation is essential, as the cause of the pain may prove elusive.

\section{Case 1}

A 55-year-old man presented with an eight month history of increasing pain in the right hip and knee. He had undergone arthrodesis of the right hip 24 years previously and had subsequently been well and pain free. He denied any trauma to the hip. The pain increased with activity and was relieved by rest. There was no history of fever, night pain or pain at rest. On examination, the hip was fused in $30^{\circ}$ of flexion, $5^{\circ}$ of external rotation and $5^{\circ}$ of adduction. There was mild tenderness in the groin, but at no other sites. There were no enlarged lymph nodes and no evidence of a hernia. Examination of the knee joint was unremarkable. A radiograph of the pelvis showed solid fusion of the right hip with two Smith-Petersen nails. There was no fracture and no evidence of loosening of the implants. Blood tests showed no abnormality and all infective markers were within normal limits. A bone scan was performed which showed no increase in uptake in the hip. An obturator oblique plain radiograph of the right hemipelvis (Fig. 1) showed that the tip of the upper Smith-Petersen nail was protruding through the cortex of the right ilium. A CT scan of the pelvis confirmed that the tip of this nail was impinging on the right iliacus muscle. To confirm that the pain was because of this impingement, a diagnostic test was undertaken with local anaesthetic (Fig. 2). Under fluoroscopic control, a needle was inserted to the tip of the nail and $14 \mathrm{ml}$ of $0.5 \%$ Marcaine injected. This was followed by resolution of the pain. Both nails were removed and he has remained pain free and mobile during the subsequent six years.

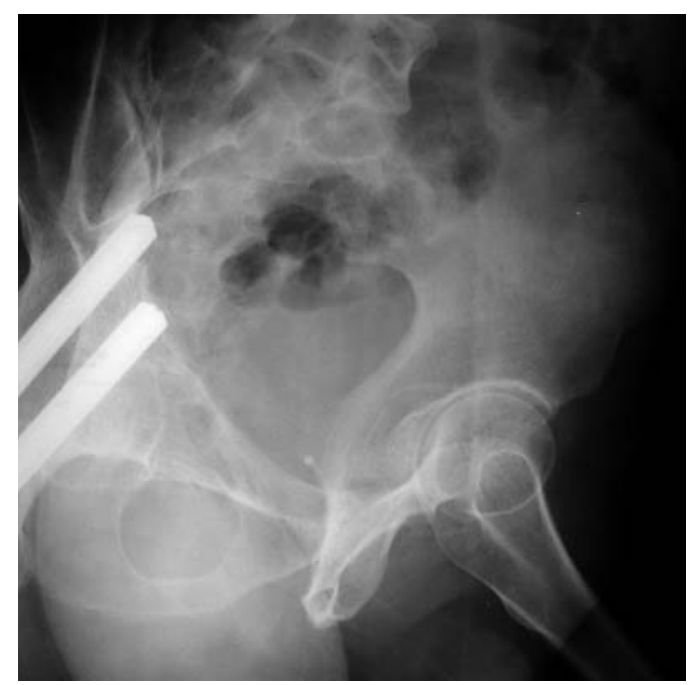

Fig. 1

Case 1. Obturator oblique radiograph of the pelvis showing the protruding implant Smith-Petersen nail. 


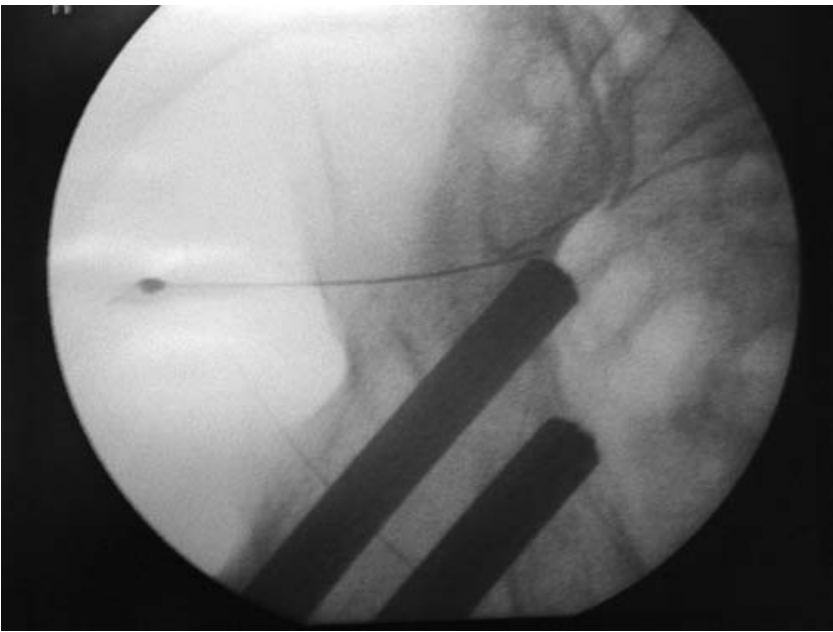

Fig. 2

Case 1. Intra-operative fluoroscopic image showing the needle adjacent to the protruding implant.

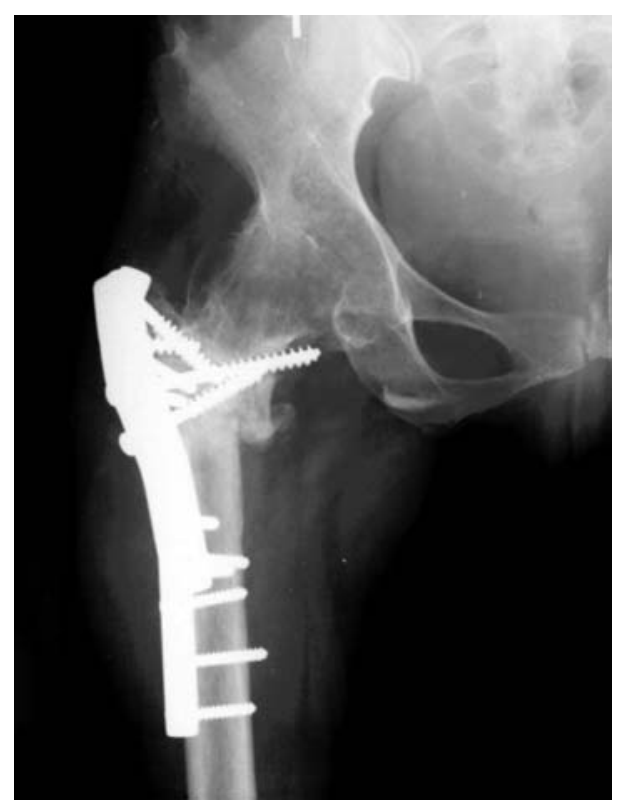

Fig. 3

Case 2. Oblique radiograph of the right hip showing the protruding screw.

\section{Case 2}

A 69-year-old woman presented with a 19-year history of pain in the right hip. She had undergone an arthrodesis of the hip 33 years previously for tuberculosis. She had fallen in 1981, sustaining a right subtrochanteric fracture. The fracture was treated by open reduction and internal fixation. The hip had remained painful since the operation. It was present at rest and aggravated by walking and prolonged sitting. She required regular analgesia.

On examination, there was a leg-length discrepancy of $6 \mathrm{~cm}$. The right hip was solidly fused in a satisfactory position. She was tender over the anterior aspect of the fused hip joint, but there was no tenderness on passive movement of the lower leg. There were no enlarged lymph nodes and no evidence of a hernia. Infective markers and a bone scan were normal. A CT scan confirmed bony ankylosis of the joint. However, an oblique radiograph with the pelvis and femur externally rotated showed the tip of a screw protruding through the neck of the femur (Fig. 3).

Injection of local anaesthestic into this site under fluoroscopic control resulted in complete resolution of the pain. The screw was removed and she has been pain free for the subsequent six years.

\section{Discussion}

The patient with an arthrodesed hip may present with ipsilateral or contralateral hip pain, ipsilateral knee pain or back pain. ${ }^{2-6}$ Late local complications include infection, fracture and implant failure. ${ }^{3,7-9}$ Most large series of hip fusions report an infection rate of around 5\% in the early post-operative period. ${ }^{3,4,7-9}$ However, there are no figures for the development of late infection. Fractures of the femoral neck, especially of the base, are not uncommon. Fractures of the femoral shaft have been reported in up to $10 \%$ of patients on long-term follow-up. $3,4,6-9$ Implant failure, usually bending or breakage, is also not uncommon. However, there has been no previous report of implant protrusion causing impingement and pain. Plain radiographs correctly orientated can be useful to detect protrusion of an implant. When impingement is suspected, the injection of local anaesthetic can be a quick and effective way of confirming the diagnosis. We would recommend the use of a longer-acting anaesthetic such as Marcaine to better observe the effect, and the subsequent removal of the impinging implant if indicated, as in the two patients reported here.

No benefits in any form have been received or will be received from a commercial party related directly or indirectly to the subject of this article.

\section{References}

1. Heusher P. Uber huftresektian wegen angeborener luxatian. Zentralb/ Chir 1884; $45: 751$.

2. Callaghan JJ, Brand RA, Pedersen DR. Hip arthrodesis: a long-term follow-up. J Bone Joint Surg [Am] 1985;67-A:1328-35.

3. Carter PJ, Wickstrom J. Arthrodesis of the hip: an assessment of results in one hundred patients. South Med J 1971;64:451-8.

4. Lipscomb PR, McCaslin FE Jr. Arthrodesis of the hip: review of 371 cases. J Bone Joint Surg [Am] 1961;43-A:923-79.

5. Sponseller PD, McBeath AA, Perpich M. Hip arthrodesis in young patients: a long-term follow-up study. J Bone Joint Surg [Am] 1984;66-A:853-9.

6. Stewart MJ, Coker TP Jr. Arthrodesis of the hip: a review of 109 patients. Clin Orthop 1969;62:136-50.

7. Breitenfelder J, Huke B. Fatigue fractures of the homolateral femur after sciatic arthrodesis. Arch Orthop Unfallchir 1974;78:248-54 (in German).

8. Chan KP, Shin JS. Brittain ischiofemoral arthrodesis for tuberculosis of the hip: an analysis of seventy-six cases. J Bone Joint Surg [Am] 1968;50-A:1341-52.

9. Watson-Jones R, Robinson WC. Arthrodesis of the osteoarthritic hip joint. J Bone Joint Surg [Br] 1956;38-B:353-77. 